\title{
Convincing the Skeptics:
}

Concrete Claims with Supporting Images Persuade Skeptical Consumers to Support Companies Promoting Corporate Social Responsibility Initiatives

\author{
Jeff Joireman \\ Associate Professor \\ Department of Marketing \\ Washington State University \\ 382 Todd Addition, Pullman, WA 99164-4730 \\ (509) 335-0191 \\ joireman@wsu.edu \\ Richie L. Liu \\ Doctoral Student \\ Department of Marketing \\ Washington State University \\ 223 Todd Addition, Pullman, WA 99164-4730 \\ (509) 335-2419 \\ richie.liu@wsu.edu \\ Ioannis Kareklas \\ Assistant Professor \\ Department of Marketing \\ Washington State University \\ 375 Todd Addition, Pullman, WA 99164-4730 \\ (509) 335-2781 \\ ioannis.kareklas@wsu.edu2
}




\title{
Convincing the Skeptics:
}

\section{Concrete Claims with Supporting Images Persuade Skeptical Consumers to Support Companies Promoting Corporate Social Responsibility Initiatives}

\begin{abstract}
Skepticism has been identified as one of the main impediments to successful CSR communication and previous research has established a robust effect of individual differences in ad skepticism on negative responses to advertising. However, little work has explored how ad skepticism impacts responses to CSR communication. Integrating work on CSR communication and ad skepticism, the present work advances a conceptual model addressing how concrete CSR claims and images supporting those claims can override skeptical consumers' less favorable response to CSR advertising. Results show that highly skeptical consumers (a) respond less favorably to CSR ads than less skeptical consumers, overall; (b) respond more favorably to CSR ads that contain a combination of concrete (vs. vague) CSR claims and images (vs. no images) supporting those claims; and (c) respond as favorably as less skeptical consumers when ads feature concrete CSR claims with supporting images. Additional results reveal that images are especially effective among highly skeptical consumers because skeptical consumers have a reduced ability to visualize advertising claims. The theoretical and practical implications of these findings are discussed.
\end{abstract}

Keywords: Corporate Social Responsibility (CSR); advertising skepticism; advertising effectiveness; vague versus concrete advertising claims; use of images in advertising. 